\title{
Household food insecurity is a risk factor for iron-deficiency anaemia in a multi-ethnic, low-income sample of infants and toddlers
}

\author{
Kyong Park ${ }^{1}$, Margaret Kersey ${ }^{2}$, Joni Geppert ${ }^{3}$, Mary Story ${ }^{1}$, Diana Cutts ${ }^{3}$ and \\ John H Himes ${ }^{1, *}$ \\ 'Division of Epidemiology and Community Health, University of Minnesota, 1300 South Second Street, Suite \\ 300, Minneapolis, MN 55454, USA: ${ }^{2}$ Department of Pediatrics, University of Minnesota, Minneapolis, MN, \\ USA: ${ }^{3}$ Department of Pediatrics, Hennepin County Medical Center, Minneapolis, MN, USA
}

Submitted 26 November 2007: Accepted 20 February 2009: First published online 1 May 2009

\begin{abstract}
Objective: The present study examines the relationships of household food security status with Fe deficiency (ID) and Fe-deficiency anaemia (IDA) among children less than 3 years of age, and associated factors that contribute to ID and IDA.

Design: Cross-sectional study and chart review. The US Food Security Survey Module was administered to adult caregivers as part of the Children's Sentinel Nutrition Assessment Project (C-SNAP). Haematological data were obtained from medical records.

Setting: A large metropolitan medical centre in Minneapolis, Minnesota, USA.

Subjects: A multi-ethnic sample of 2853 low-income children aged $<36$ months who received care at the medical centre.

Results: Among the caregivers, $23 \cdot 3 \%$ reported low household food security and $11 \cdot 6 \%$ reported very low household food security (VLFS). After controlling for background factors, children from households with VLFS were almost twice as likely to have IDA than were children from households with high or marginal food security $(\mathrm{OR}=1.98,95 \%$ CI $1 \cdot 11,3 \cdot 53)$; the corresponding associations for ID were not statistically significant.

Conclusions: The prevalence of IDA in early childhood is significantly larger in low-income infants and toddlers living in VLFS households. Asian, Hispanic and African-American children have elevated prevalences of ID and IDA. Breastfeeding may be associated with elevated ID and IDA, while participation in the Special Supplemental Nutrition Program for Women, Infants, and Children (WIC) may be protective for ID.
\end{abstract}

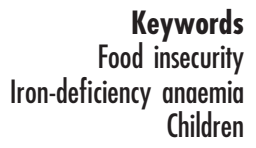

Although extreme forms of hunger are uncommon in the USA, many American households do experience food insecurity and less severe forms of hunger ${ }^{(1)}$. Food insecurity has been defined as limited or uncertain availability of nutritionally adequate and safe foods ${ }^{(2,3)}$. The most recent nationally representative food security survey documented that $11 \%$ of US households were foodinsecure in $2005^{(1)}$. Of these households, about one-fifth showed a recurring pattern of hunger due to inadequate resources for one or more of their adult and/or child members at some time during this period ${ }^{(1)}$.

Studies have shown that food insecurity is associated with poor academic performance, emotional difficulties and poorer health among children ${ }^{(4-7)}$. Food insecurity during the first three years of life can have substantial negative impacts on subsequent physiological, behavioural and cognitive development ${ }^{(8)}$. Also, hungry children are more likely to have frequent physician visits, despite lower levels of health insurance ${ }^{(9)}$. Recent research has provided evidence that food insecurity is associated with overweight in female adults ${ }^{(10)}$ as well as in children ${ }^{(11)}$.

Fe deficiency (ID) and Fe-deficiency anaemia (IDA) are among the most common nutritional deficiencies in the USA and worldwide ${ }^{(12,13)}$. Infants and toddlers are at especially high risk for ID because of their rapid rates of growth and frequently inadequate intakes of dietary Fe. IDA during the first two years of life is an established correlate of impairments in cognitive, mental and psychomotor development that persist even after treatment of the $\operatorname{IDA}^{(14-17)}$. 
ID is related to poverty in children. Looker et al. ${ }^{(12)}$ reported that the prevalence of ID is higher among children living at or below the poverty level than among those living above the poverty level. Alaimo et $a l^{(4)}$ reported that low-income children were more likely than high-income children to be Fe-deficient. Poverty is clearly related to food insecurity even though income-based poverty measures may not give an accurate picture of food insecurity. According to Rose et al. ${ }^{(18)}$, poverty status is not a good indicator of food insecurity. The use of poverty status per se as an indicator of food insecurity would overlook an appreciable percentage of households that were food-insecure and would incorrectly identify many households that were not.

An important study by Skalicky et al. ${ }^{(19)}$ found child food insecurity to be associated with IDA (adjusted $\mathrm{OR}=2 \cdot 4)$ in Boston children aged 6-36 months. These results indicate that young children in households with the two categories of most severe child-level food insecurity were more than twice as likely to have IDA as children who were food-secure. No corresponding significant associations were found for children with anaemia but without ID or with ID but without anaemia. Potential confounders were controlled for in the analyses, including US-born caregiver, caregiver education, welfare status, household size and whether the child was breastfed. Nevertheless, the individual contributions of these and other covariates to IDA occurrence were not reported in the multivariable analysis, so we are left uninformed concerning other possibly important risk factors for IDA as it relates to food insecurity. Also, children aged $<6$ months were excluded from the analyses.

The results of Skalicky et al. ${ }^{(19)}$ prompt one to enquire whether food insecurity at the household level, a much more common and less severe status than child-level food insecurity ${ }^{(11)}$, is related to ID and IDA, and what other child and family characteristics may be risk factors for ID and IDA. Even though measures of food insecurity were not designed to be measures of nutritional status per se, it is important to determine if household food insecurity is associated with biological indicators of nutritional risk. The associations of ID and IDA with poverty suggest that young children in food-insecure households are at additional risk for ID and IDA. If so, the results would provide additional validation for the measures of food security and they may have implications for both policy and clinical practice.

\section{Methods}

\section{Study population}

We conducted a retrospective study as part of the Children's Sentinel Nutrition Assessment Project (C-SNAP) ${ }^{(20)}$. The sampling frame included 5033 visits for children aged less than 3 years living in low-income households whose caregivers utilized Hennepin County Medical Center in
Minneapolis, Minnesota, USA, between September 1998 and December 2003. As part of C-SNAP protocol, consenting adult caregivers accompanying children $<3$ years of age at acute- and primary-care clinics and at hospital emergency departments were interviewed in private settings by trained interviewers. Caregivers of critically ill or injured children were not approached. Potential respondents were excluded if they did not speak English, Spanish or Somali; if they were not knowledgeable about the child's household; or if they refused consent for any reason.

\section{Data collection}

The survey interview included questions concerning household characteristics, caregiver and child characteristics, federal assistance programme participation, food security and child health. Food security status was evaluated using responses to the core set of eighteen questions taken from the US Food Security Survey Module ${ }^{(21,22)}$ and scored in accordance with established procedures.

The chief independent variable in analyses was each child's household food-security status, categorized into three categories based on conditions during the 12 months prior to the interview.

1. High/marginal food security (HFS): caregivers answered no more than two of the eighteen scale questions affirmatively, indicating no or minimal evidence of food insecurity.

2. Low food security (LFS): caregivers answered between three and seven of the eighteen scale questions affirmatively, showing concerns about adequacy of the household food supply and adjustments to household food management, including reduced quality of food and unusual coping patterns.

3. Very low food security (VLFS): caregivers answered eight or more of the eighteen scale items affirmatively, indicating the food intakes for adults and children in the household were reduced to the extent that members of the household repeatedly experienced the physical sensations of hunger during the previous 12 months due to lack of resources.

Because the present research focused on the food insecurity issue at the household level, the children's specific food-insecurity categories were not considered.

Most blood samples were obtained as part of routine primary care at age 9-12 months or 15-18 months and from screening tests for ID and $\mathrm{Pb}$ exposure. Blood samples were obtained following Medical Center routine protocols for phlebotomy and handling of blood products. In this primary-care setting, the standard of care was to obtain a complete blood count by Coulter STKS machine (using the cynamethaemoglobin spectrographic measurement after the cells had been lysed). Haematological results were obtained from medical-record audits of all children whose caregivers were interviewed. All study procedures were approved by the appropriate institutional 
review boards at Hennepin County Medical Center and at the University of Minnesota.

\section{Statistical analysis}

The dependent or outcome variables were ID and IDA, and the available haematological indicators were $\mathrm{Hb}$ concentration, mean cell volume (MCV) and red-bloodcell distribution width (RDW). Criteria for Fe status were based on current guidelines from the Centers for Disease Control and Prevention ${ }^{(13)}$ and recommendations of Domellof et $a l^{(23)}$, using age-specific criteria (Table 1). Three Fe status groups were defined: Fe-sufficient without anaemia; Fe deficiency without anaemia (ID); and Fe-deficiency anaemia (IDA).

Data were cleaned following the C-SNAP criteria ${ }^{(20)}$. We only included children for whom the haematological measures (Hb, RDW and MCV) and food-security measures were available and who were $<3$ years of age at the time of the blood draw. Children were included for analysis if the interview was conducted within 12 months prior to, or within 12 months following, the date of the blood sample. This time window was chosen to maximize sample size, and assuming that the household foodsecurity status was probably rather stable over time so that even if the blood sample followed the period explicitly covered by the food-security questions, associations with Fe status should still be valid. Preliminary analyses indicated that the relationships between food insecurity and IDA were similar for children with interviews before and after the blood sample. For example, among children with an interview before the blood sample, those living in households experiencing VLFS had odds of IDA of $1 \cdot 83$, compared with those in HFS households. A similar relationship was found among children with the interview after the blood sample (OR $=1 \cdot 88)$.

Finally, in cases where children and their caregivers visited the hospital and were interviewed multiple times during the sampling period, we randomly selected one interview and an associated blood sample for analysis. After all exclusions, 2853 children comprised the sample for analysis.

Race/ethnicity was categorized into six groups: AfricanAmerican, African immigrant, Hispanic, Asian, Native American and Caucasian. Most of the African immigrant children were from families who were refugees from war-torn African countries like Somalia, Sudan and Congo. The immigrant children were considered separately from African-Americans whose families had a long history of living in America because the immigrant families may have added barriers to food security such as language and cultural factors. The few Asian children were primarily from South-East Asian countries, such as Laos, Cambodia and Vietnam, and the American Indian children were mostly from the Ojibwe and Dakota/Lakota Sioux tribes.

Logistic regression models were used to estimate the odds of ID or IDA among children from LFS or VLFS households compared with those from HFS households.
Table 1 Criteria for iron deficiency (ID) and iron-deficiency anaemia (IDA) by age group*

\begin{tabular}{lcclllll}
\hline & \multicolumn{2}{c}{ ID } & & \multicolumn{3}{c}{ IDA } \\
\cline { 2 - 3 } \cline { 7 - 7 } Age (months) & MCV (fl) & RDW (\%) & & Hb (g/l) & MCV (fl) & RDW (\%) \\
\hline$<5$ & $<73$ & $>14$ & & $<105$ & $<73$ & $>14$ \\
$5-7 \cdot 49$ & $<71$ & $>14$ & & $<105$ & $<71$ & $>14$ \\
$7 \cdot 5-10 \cdot 49$ & $<71$ & $>14$ & & $<100$ & $<71$ & $>14$ \\
$10 \cdot 5-23 \cdot 99$ & $<77$ & $>14$ & & $<110$ & $<77$ & $>14$ \\
$24-35 \cdot 99$ & $<77$ & $>14$ & & $<111$ & $<77$ & $>14$ \\
\hline
\end{tabular}

MCV, mean cell volume; RDW, red-blood-cell distribution width.

${ }^{*}$ Based on current guidelines from the Centers for Disease Control and Prevention $^{(13)}$ and recommendations of Domellof et al. ${ }^{(23)}$.

Various household and child-level characteristics (listed in Tables 2 and 3) that might be related with either food security or ID/IDA were considered as potential independent variables in analysing the associations between food security and ID/IDA. Among them, child's age, gender, race, US-born status, breast-feeding, blood $\mathrm{Pb}$ levels, health insurance type and current participation status in the Special Supplemental Nutrition Program for Women, Infants, and Children (WIC), which were associated with both food security and ID/IDA, were included in the models as possible confounding variables or important demographic determinants. For some of these variables there were missing data, so the final models have a reduced number of cases. Because of the many variables concerned, a formal analysis of the potential effects of the patterns of missing data is beyond the scope of this report. Plasma $\mathrm{Pb}$ concentration was considered an important covariate because $\mathrm{Pb}$ may interfere with $\mathrm{Hb}$ synthesis $^{(24)}$, and it was used as a continuous variable in the models because it accounted for a graded response with $\mathrm{Hb}$ better than using categories of blood $\mathrm{Pb}$ concentration.

Three logistic regression models were tested. Model 1 estimated crude associations between food security status (HFS, LFS and VLFS) and ID/IDA. Model 2 adjusted for child's age, gender, race and US-born status. We further adjusted for breast-feeding, WIC participation status, health insurance type and plasma $\mathrm{Pb}$ concentration in Model 3. All statistical interactions among variables were tested and none were statistically significant. Because of missing data for some variables the number of cases used in some analyses varied slightly.

Data analyses were conducted using the SAS statistical software package version 9·1 (SAS Institute, Cary, NC, USA), and a 0.05 probability level of type 1 error was used to determine statistical significance.

\section{Results}

In our survey, $99 \%$ of respondents were children's primary caregivers. Table 2 summarizes the sample characteristics and crude prevalences of household food-security status - HFS, LFS and VLFS - by child and household 


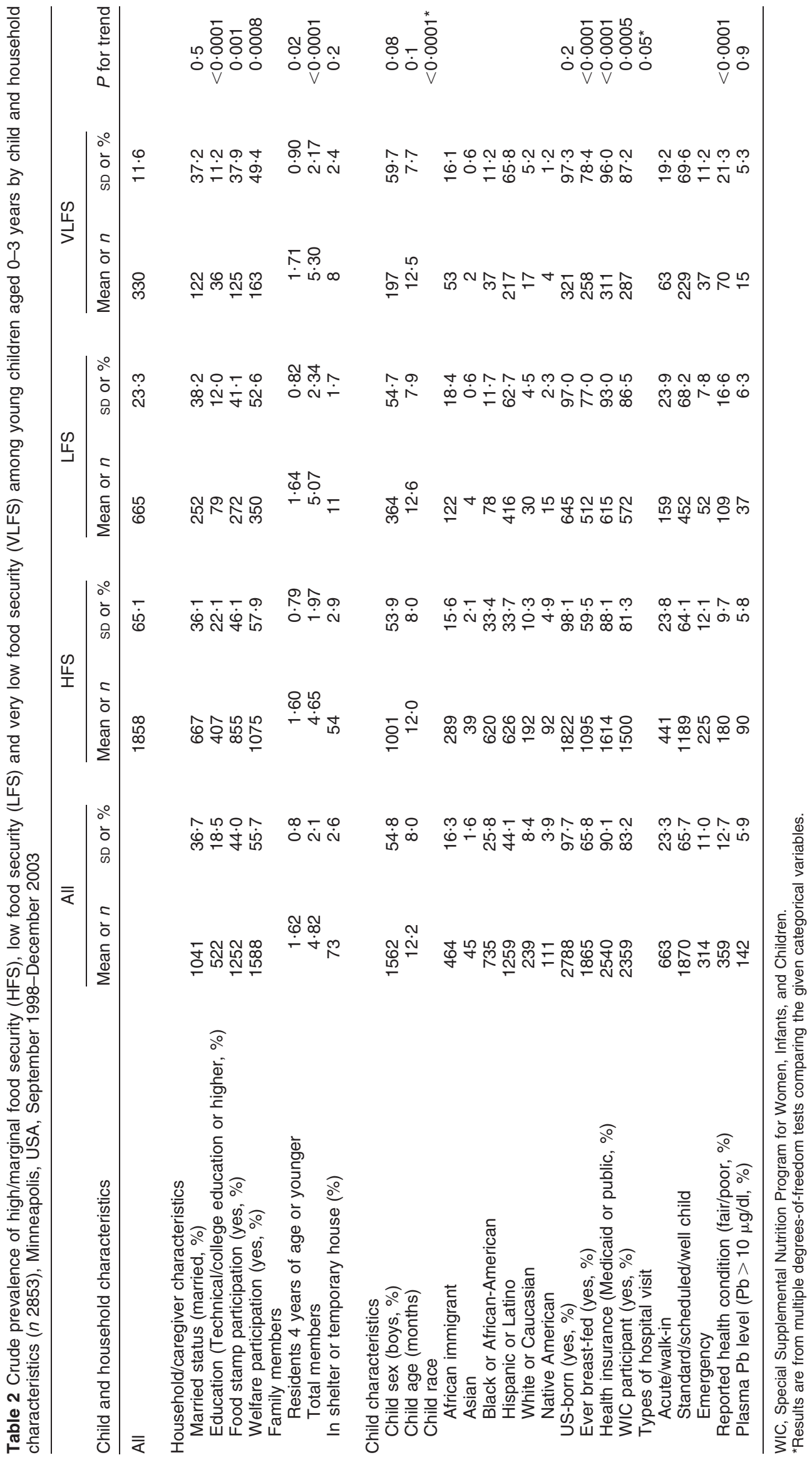


Table 3 Crude associations of iron deficiency (ID) and iron-deficiency anaemia (IDA) among young children aged 0-3 years by child and household characteristics ( $n$ 2853), Minneapolis, USA, September 1998-December 2003

\begin{tabular}{|c|c|c|c|c|c|}
\hline \multirow[b]{2}{*}{ Child and household characteristics } & \multirow[b]{2}{*}{ Reference category } & \multicolumn{2}{|c|}{ ID } & \multicolumn{2}{|c|}{ IDA } \\
\hline & & Crude OR & $95 \% \mathrm{Cl}$ & Crude OR & $95 \% \mathrm{Cl}$ \\
\hline \multicolumn{6}{|l|}{ Household/caregiver characteristics } \\
\hline Married status (married) & Single & $0 \cdot 87$ & $0 \cdot 69,1 \cdot 11$ & 0.91 & $0.61,1 \cdot 36$ \\
\hline Education (Technical/college education or higher) & High school or lower & 0.90 & $0.67,1 \cdot 23$ & $1 \cdot 03$ & $0.63,1.69$ \\
\hline Food stamp participation (yes) & No & $0 \cdot 85$ & $0 \cdot 68,1 \cdot 08$ & $0 \cdot 85$ & $0 \cdot 57,1 \cdot 26$ \\
\hline Welfare participation (yes) & No & $0 \cdot 76$ & $0.61,0.96$ & $0 \cdot 84$ & $0.57,1.23$ \\
\hline \multicolumn{6}{|l|}{ Family members } \\
\hline Residents 4 years of age or younger & Continuous & 1.03 & $0 \cdot 90,1 \cdot 19$ & $0 \cdot 91$ & $0 \cdot 71,1 \cdot 17$ \\
\hline Total members & Continuous & $1 \cdot 00$ & $0.95,1.06$ & 0.94 & $0.85,1.04$ \\
\hline Type of house (shelter or temporary house) & House/apartment & $0 \cdot 81$ & $0 \cdot 37,1 \cdot 79$ & $0 \cdot 35$ & $0 \cdot 05,2 \cdot 54$ \\
\hline \multicolumn{6}{|l|}{ Child characteristics } \\
\hline Child sex (boys) & Girls & $1 \cdot 26$ & $1.00,1.59$ & $1 \cdot 46$ & $0 \cdot 98,2 \cdot 18$ \\
\hline Child age (months) & Continuous & 1.08 & $1.06,1.09$ & 1.09 & $1 \cdot 06,1 \cdot 11$ \\
\hline \multicolumn{6}{|l|}{ Child race } \\
\hline African immigrant & White or Caucasian & 0.94 & $0.51,1.73$ & $6 \cdot 32$ & $0 \cdot 82,48 \cdot 88$ \\
\hline Asian & White or Caucasian & $3 \cdot 73$ & $1 \cdot 58,8 \cdot 81$ & $17 \cdot 00$ & $1 \cdot 73,167.33$ \\
\hline Black or African-American & White or Caucasian & 1.92 & $1 \cdot 12,3 \cdot 28$ & $11 \cdot 54$ & $1 \cdot 57,84 \cdot 78$ \\
\hline Hispanic or Latino & White or Caucasian & $2 \cdot 00$ & $1 \cdot 19,3 \cdot 36$ & $10 \cdot 67$ & $1 \cdot 47,77 \cdot 47$ \\
\hline Native American & White or Caucasian & $1 \cdot 15$ & $0.50,2.67$ & $6 \cdot 61$ & $0 \cdot 68,64 \cdot 28$ \\
\hline US-born (yes) & No & $0 \cdot 28$ & $0 \cdot 16,0.48$ & $0 \cdot 31$ & $0.14,0.69$ \\
\hline Ever breast-fed (yes) & No & $1 \cdot 32$ & $1.02,1.69$ & 1.57 & $1 \cdot 01,2 \cdot 44$ \\
\hline Health insurance (Medicaid or public, yes) & No & 0.67 & $0.47,0.95$ & $1 \cdot 17$ & $0.59,2.35$ \\
\hline WIC participant (yes) & No & 0.54 & $0 \cdot 41,0 \cdot 71$ & 0.55 & $0.35,0.85$ \\
\hline \multicolumn{6}{|l|}{ Types of hospital visit } \\
\hline Acute/walk-in & Standard/scheduled/well child & $0 \cdot 86$ & $0 \cdot 64,1 \cdot 15$ & $0 \cdot 76$ & $0.45,1 \cdot 27$ \\
\hline Emergency & Standard/scheduled/well child & $1 \cdot 44$ & $1 \cdot 03,2 \cdot 01$ & $1 \cdot 56$ & $0.92,2.66$ \\
\hline Reported health condition (fair/poor) & Excellent/good & $1 \cdot 40$ & $1 \cdot 02,1 \cdot 92$ & $1 \cdot 86$ & $1 \cdot 15,3 \cdot 01$ \\
\hline Plasma $\mathrm{Pb}$ level $(\mathrm{Pb}>10 \mu \mathrm{g} / \mathrm{dl})$ & $\leq 10 \mu \mathrm{g} / \mathrm{dl}$ & $1 \cdot 84$ & $1 \cdot 20,2 \cdot 82$ & 1.42 & $0.68,2.99$ \\
\hline
\end{tabular}

WIC, Special Supplemental Nutrition Program for Women, Infants, and Children.

characteristics. Approximately half of caregivers reported they received food stamp or welfare benefits, and WIC participation was even higher (83\%) in this sample. The average age of the children was $12 \cdot 2$ (sD $8 \cdot 0$ ) months, and the racial/ethnic composition of the sample was primarily Hispanic (44\%), African-American (26\%) and African immigrants (16\%), although most of them were born in the USA (98\%). Overall, $65 \%$ of caregivers reported HFS, $23 \%$ reported LFS and $12 \%$ reported VLFS. The vast majority of children (94\%) had plasma $\mathrm{Pb}$ in the normal range $(\mathrm{Pb} \leq 10 \mu \mathrm{g} / \mathrm{dl})$.

Crude associations indicated that welfare or food stamp recipients tended to be protected from lower food security (Table 2) and less-educated caregivers were more likely to have lower food security. Children from households with LFS or VLFS were more likely than those with HFS to have had more family members, to have participated in WIC and public health insurance, and to have been ever breast-fed. Hispanic children were most likely to live in a household with LFS or VLFS.

The crude associations between background variables and prevalence of ID and IDA are shown in Table 3. Children with ID or IDA were more likely to be older, breast-fed and reported to have 'fair or poor' health. Children who were US-born and who currently participated in WIC were less likely to have ID or IDA. Differences were also apparent by race: Asian children were most likely to have ID or IDA,
Table 4 Summary odds ratios for iron deficiency (ID) and irondeficiency anaemia (IDA) with food security status among young children aged $0-3$ years by child and household characteristics (n 2853), Minneapolis, USA, September 1998-December 2003

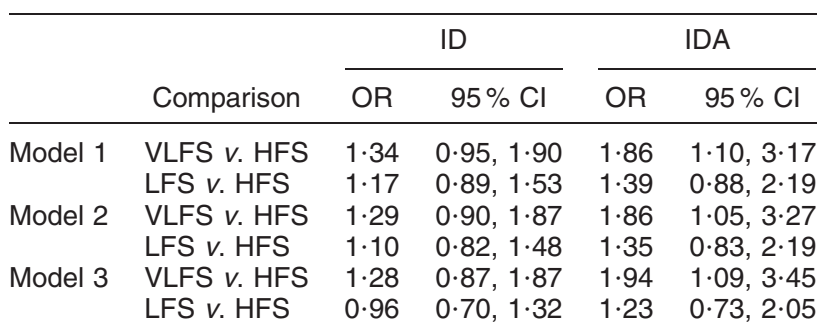

Model 1, crude model; Model 2, adjusted for demographic variables (child age, race, sex and US-born status); Model 3, Model 2 plus plasma Pb level, breast-feeding and participation in WIC (Special Supplemental Nutrition Program for Women, Infants, and Children); VLFS, very low food security; HFS, high/marginal food security; LFS, low food security.

those from African immigrant households were least likely to have ID, and Caucasian children were the least likely to have IDA. Welfare and public insurance may have been protective for ID, whereas such benefits were not apparent for IDA.

Table 4 includes crude and adjusted summary odds ratios for ID and IDA, according to category of food security, in three logistic models. The models estimating ID comparing categories of food security were not statistically significant. In contrast, children in households with VLFS had 1.86 greater odds of IDA compared with those with HFS (95\% 
Table 5 Details of Model 3 (logistic regression analysis) for variables associated with iron deficiency (ID) and iron-deficiency anaemia (IDA), adjusting for the listed variables, among young children aged 0-3 years ( $n$ 2360), Minneapolis, USA, September 1998-December 2003

\begin{tabular}{|c|c|c|c|c|c|}
\hline \multirow[b]{2}{*}{ Variables } & \multirow[b]{2}{*}{ Comparison } & \multicolumn{2}{|c|}{ ID } & \multicolumn{2}{|c|}{ IDA } \\
\hline & & OR & $95 \% \mathrm{Cl}$ & OR & $95 \% \mathrm{Cl}$ \\
\hline \multirow[t]{2}{*}{ Food insecurity (ref: HFS) } & VLFS & $1 \cdot 36$ & $0.93,2.01$ & 1.98 & $1 \cdot 11,3 \cdot 53$ \\
\hline & LFS & 0.95 & $0 \cdot 69,1 \cdot 31$ & $1 \cdot 12$ & $0.66,1.90$ \\
\hline Gender (ref: girls) & Boys & $1 \cdot 41$ & $1.09,1.83$ & $1 \cdot 74$ & $1 \cdot 12,2 \cdot 70$ \\
\hline \multirow[t]{5}{*}{ Child race (ref: white) } & African immigrant & $0 \cdot 81$ & $0.39,1.68$ & 3.54 & $0.44,28.59$ \\
\hline & Asian & $5 \cdot 40$ & $2 \cdot 03,14 \cdot 37$ & $15 \cdot 63$ & $1 \cdot 51,161 \cdot 46$ \\
\hline & Black or African-American & $2 \cdot 81$ & $1 \cdot 48,5 \cdot 32$ & $12 \cdot 87$ & $1 \cdot 71,96 \cdot 83$ \\
\hline & Hispanic or Latino & 1.93 & $1.03,3.59$ & $6 \cdot 63$ & $0 \cdot 89,49 \cdot 29$ \\
\hline & Native American & 1.92 & $0.76,4.83$ & $7 \cdot 97$ & $0 \cdot 80,79 \cdot 36$ \\
\hline Born in USA (ref: no) & Yes & 0.48 & $0.25,0.93$ & 0.54 & $0 \cdot 20,1 \cdot 46$ \\
\hline WIC participant (ref: no) & Yes & 0.72 & $0.53,0.99$ & 0.65 & $0.39,1.08$ \\
\hline Ever breast-fed (ref: no) & Yes & $1 \cdot 68$ & $1 \cdot 21,2 \cdot 33$ & $2 \cdot 27$ & $1 \cdot 29,4 \cdot 02$ \\
\hline Health insurance (ref: private) & Medicaid or public & 0.69 & $0.46,1.04$ & $1 \cdot 22$ & $0.55,2 \cdot 71$ \\
\hline Age in months & Continuous & $1 \cdot 07$ & $1.05,1.08$ & $1 \cdot 07$ & $1 \cdot 05,1 \cdot 10$ \\
\hline $\mathrm{Pb}(\mu \mathrm{g} / \mathrm{dl})$ & Continuous & $1 \cdot 04$ & $1.01,1.06$ & $1 \cdot 01$ & $0.97,1.06$ \\
\hline
\end{tabular}

HFS, high/marginal food security; VLFS, very low food security; LFS, low food security; WIC, Special Supplemental Nutrition Program for Women, Infants, and Children.

CI 1·10, 3·17). This association remained largely unchanged after adjustment for demographic variables (Model 2; $\mathrm{OR}=1 \cdot 86,95 \% \mathrm{CI} 1 \cdot 05,3 \cdot 27)$ and after further adjustments for $\mathrm{Pb}$ level, breast-feeding and WIC participation (Model 3; $\mathrm{OR}=1 \cdot 94,95 \%$ CI $1 \cdot 09,3 \cdot 45$ ).

Table 5 shows the detailed associations between ID and IDA, background variables and food security from fully adjusted Model 3. Boys were approximately $40 \%$ more likely than girls to have ID (95\% CI 1.09, 1.83) and approximately $70 \%$ more likely to have IDA (95\% CI $1 \cdot 12$, 2.70). Compared with white children, Asian and AfricanAmerican children had much higher prevalences of both ID (Asian: $\mathrm{OR}=5 \cdot 40,95 \%$ CI 2.03, 14.37; African-American: $\mathrm{OR}=2 \cdot 81,95 \%$ CI $1 \cdot 48,5 \cdot 32$ ) and IDA (Asian: $\mathrm{OR}=15 \cdot 63$, 95\% CI 1.51, 161.5; African-American: OR $=12 \cdot 87,95 \% \mathrm{CI}$ $1 \cdot 71,96 \cdot 83)$. Hispanic children had elevated prevalences of ID $(\mathrm{OR}=1.93,95 \% \mathrm{CI} 1 \cdot 03,3 \cdot 59)$ compared with white children, but the association with IDA was not significant. WIC participation was inversely associated with ID in the fully adjusted model (OR $=0 \cdot 72,95 \%$ CI 0.53, 0.99), while the association between WIC and IDA was not significant $(\mathrm{OR}=0 \cdot 65,95 \%$ CI $0 \cdot 39,1 \cdot 08)$. Breast-fed children were about $1 \cdot 7$ times (95\% CI $1 \cdot 21,2 \cdot 33)$ and $2 \cdot 3$ times (95\% CI $1 \cdot 29,4 \cdot 02$ ) more likely to have ID and IDA, respectively, than bottle-fed children. The adjusted odds of having ID increased with both increasing child age $(\mathrm{OR}=1 \cdot 07,95 \%$ CI $1 \cdot 05,1 \cdot 08)$ and plasma $\mathrm{Pb}$ concentration $(\mathrm{OR}=1 \cdot 04$, 95\% CI $1 \cdot 01,1 \cdot 06$ ), but only the association between age and IDA was statistically significant $(\mathrm{OR}=1 \cdot 07$, 95\% CI $1 \cdot 05,1 \cdot 10)$.

\section{Discussion}

Children aged $<36$ months who were living in households considered VLFS were almost twice as likely to have
IDA compared with those in HFS households, independent of age, gender, WIC participation, race, US-born status, breast-feeding, health insurance type and plasma $\mathrm{Pb}$ concentration (adjusted OR $=1 \cdot 98,95 \%$ CI 1·11, 3.53).

Based on data from the National Health and Nutrition Examination Survey (NHANES) 1999-2000, the prevalence of ID among US toddlers aged 1-2 years was $7 \%$, and the prevalence of IDA was $2 \%{ }^{(25)}$. The corresponding crude prevalences from our study (1-2 years old, $n$ 1428) were $18 \cdot 4 \%$ for ID and $6 \cdot 3 \%$ for IDA; thus, somewhat higher than the national levels. This may be due to the consistently low-income status and the diverse race/ethnic composition of our sample, which in general is at greater risk of ID and IDA. The national data are not reported in other age groups that allow direct comparisons.

The prevalences of ID and IDA in our sample increased with increasing age. This is in contrast to the decreasing age-related patterns in anaemia, ID and IDA seen in the few available data sets reporting these trends in very young children ${ }^{(26-28)}$. Because our sample is based on clinical intake, it is difficult to generalize the age patterns observed in our sample to the whole population or to identify specific factors that systematically might select for relatively higher prevalences with age among toddlers. Consequently, the causes of the age pattern in our sample are unknown.

In our sample gender differences in ID and IDA among infants and toddlers remained after controlling for other variables. Boys were approximately $40 \%$ more likely to have ID and approximately $70 \%$ more likely to have IDA than girls. This is consistent with the findings from US national data ${ }^{(27)}$ and from Domellof et al. $^{(29)}$, who found lower $\mathrm{Hb}, \mathrm{MCV}$ and ferritin, and higher $\mathrm{Zn}$ protoporphyrin and transferrin receptors, in boys than girls at 4, 6 and 9 months in a randomized trial in Sweden. However, little is known about this gender difference 
regarding prevalent ID and IDA. Research regarding the origins of this apparent gender difference should probably focus both on aspects related to possible differential feeding behaviours, as well as possible biological aspects; for example, at these ages males may have smaller red cell indices of ID and IDA than females for the same levels of Fe stores.

Race/ethnic-related patterns reported for the NHANES 1999-2000 survey were limited to three classifications in children 1-3 years of age: prevalences of ID and IDA were higher in Mexican-American (16.9\%, 5.5\%) and nonHispanic black children $(8 \cdot 0 \%, 3 \cdot 5 \%)$ than in white children $(5 \cdot 7 \%, 1 \cdot 2 \%)^{(27)}$. Among children in the Pediatric Nutrition Surveillance System, including children from 24 to 48 moths of age, black and Asian children consistently had increased incidence and persistence of anaemia compared with white, Hispanic and Native American children ${ }^{(28)}$. The prevalences of ID and IDA in our sample were markedly different among race/ethnic groups, with much higher levels among the minority children. The groups of Asian and Native American children were rather small in our sample (thirtyfour and seventy-seven children respectively in the final model), so they may not be representative of the larger populations. Nevertheless, the relative excess cases of ID and IDA in Asian children relative to white children persisted in the adjusted logistic models. Some of these Asian cases may be due to a relatively high prevalence of thalassaemias in the Asian children. Haemoglobinopathies were not specifically screened for in our sample. Dietary choices and practices and food choices differ considerably among the immigrant families compared with those in the other race/ethnic groups but we have no hard data to explain the observed differences.

Children with ID or IDA were more likely to have been ever breast-fed, and approximately $66 \%$ of caregivers reported their children were ever breast-fed in our sample. Human milk is known to contain highly bioavailable $\mathrm{Fe}^{(30,31)}$, highest in early milk and decreasing over time ${ }^{(32,33)}$. Recent studies have reported that longer duration of exclusive breast-feeding ${ }^{(34)}$ and anaemic mothers $^{(35,36)}$ are associated with increasing risk of ID and IDA in infants and toddlers. Considering the high prevalence of low-income households in our sample, a relatively high proportion of the mothers may have had anaemia or low Fe status or may have been more likely to breast-feed their children for longer periods. Unfortunately, we could not examine maternal Fe status and the duration of exclusive breast-feeding in our survey because such data were not collected, so such relationships are entirely speculative. Careful study with designs that can separate effects of breast-feeding duration from maternal Fe status in low-income US populations would be most informative on this point, because the anticipated duration of breast-feeding among US mothers is probably much less than those associated with infant anaemia in developing countries ${ }^{(36)}$.
The significant association between WIC participation and ID in these young children suggests that the nation's largest and most important nutrition programme for young children is protective of children's health in our sample. WIC provides a monthly package of nutritious foods such as Fe-fortified infant formula, infant cereal, eggs and Fe-fortified breakfast cereal to meet part of the dietary needs. Our findings of beneficial effects of programme participation are consistent with several previous studies ${ }^{(37-39)}$. Miller et al. ${ }^{(37)}$ found that serum ferritin concentration was significantly increased after participating in the WIC programme for infants at both 6 months and 9 months of age. Owen et $a l^{(38)}$ also observed that the prevalence of IDA was lower among children participating in WIC than among those not participating in WIC. The US Department of Agriculture National WIC Evaluation study of infants and children ${ }^{(39)}$ showed that WIC recipients had higher daily intake of Fe than nonrecipients. Our results support the position that effective implementation of the WIC programme may lead to improvements of child Fe status.

As discussed above, there may be negative effects of longer duration of exclusive breast-feeding, especially in anaemic mothers in this racially diverse low-income population. By expanding WIC's coverage in this population (including immigrants), mothers' Fe levels may be improved during pregnancy and lactation through consuming high-Fe foods and supplements. In addition, for infants, the introduction of nutritionally adequate complementary foods (e.g. Fe-fortified infant foods) is provided at 6 months of age with an option of continued breast-feeding. Therefore, through expanded WIC resources, infants from lowincome families may benefit both directly and indirectly regarding their Fe status.

Studies examining the associations between household food security and ID or IDA are rare, especially in young children from low-income households, who are particularly vulnerable to food insecurity. In addition, the race/ ethnic composition of our sample is diverse, including six different ethnicities (African-American, African immigrant, Hispanic, Asian, Native-American and Caucasian), thus allowing us to examine if the associations between food insecurity and ID/IDA differ by race and which race/ ethnicity groups are more vulnerable to low or very low food security and to ID or IDA.

Several limitations of our study should be noted. Our results reflect the ID and IDA status of the children served by our medical centre, a chief provider of services to children from low-income families in the Twin Cities metropolitan area. Nevertheless, we cannot be sure that they are fully representative of the corresponding race/ ethnic populations in the community because the children comprise a clinical population and the sample method of C-SNAP was basically to approach caregivers accompanying young children seeking care (acute primary-care clinics and hospital emergency departments). Dietary practices 
that probably vary among the race/ethnic groups may contribute to ID and IDA. Unfortunately, we have no data to document and evaluate the contributions of variable dietary practices. To the degree that the pattern of missing data for some variables (other than ID/IDA and food security) was non-random and these patterns were related to ID and IDA, our models may have mis-specified some associations. Nevertheless, because the full models we used controlled for a wide range of background factors, we believe that the associations between household food security and ID and IDA should not be appreciably affected.

While we are reasonably confident that our reported associations are valid, we did not always use haematological data that followed the measured exposure to child food insecurity in an appropriate temporal sequence. Food security status and indicators of ID and IDA were obtained at different times in our study although always within 12 months. Because of the chronic nature of food insecurity we believe that the 12-month window is reasonable proximity and should not affect the general interpretation of results.

In this low-income sample of young children in Minnesota, household-level VLFS was associated with IDA. Accordingly, VLFS is not only an indicator of food insecurity per se but also identifies households with children at increased risk of a specific nutrient deficiency; in this case Fe. IDA is associated with adverse health outcomes such as impairments in cognitive, mental and psychomotor development ${ }^{(14-17)}$, and it has a significant and pervasive impact on the health and development of children.

It is fitting that the Healthy People 2010 objectives include both increasing the food security of American households and reducing ID in young children ${ }^{(40)}$. While the expressed purpose of increasing household food security is to reduce hunger, our data suggest that an additional benefit may be to reduce ID as well. Given that the expected prevalences of IDA are quite low, however, it is unlikely that using household food security as a screener would appreciably enhance the identification of young children with IDA that are already within the health-care system. It does seem appropriate to determine in future research whether household food security is a sufficiently powerful indicator of health risk that it is associated with other indicators of nutritional status.

\section{Acknowledgements}

This research received no specific grant from any funding agency in the public, commercial or non-profit sectors. None of the authors has any conflicts of interest with regard to this research or findings. K.P. conducted this research as part of her graduate studies in public health. She conducted the statistical analyses and developed first drafts of the manuscript. M.K. helped develop the research questions and did some preliminary analysis.
She reviewed the manuscript and findings. J.G. was responsible for finding hospital records and for supporting the coding of the data. She reviewed the manuscript and findings. M.S. helped develop the approach and reviewed the manuscript and findings. D.C. helped develop the research questions and reviewed and revised the manuscript. J.H.H. was K.P.'s academic advisor, helped develop the statistical analyses and revised the manuscript. We have no acknowledgements to include with this paper.

\section{References}

1. Nord M, Andrews MS \& Carlson SJ (2006) Household Food Security in the United States, 2005. Food Assistance and Nutrition Research Report no. 29, pp. 1-69. Washington, DC: US Department of Agriculture.

2. Anderson S (1990) Core indicators of nutritional state for difficult-to-sample populations. J Nutr 120, Suppl. 11, 1559-1600.

3. Campbell CC (1991) Food insecurity: a nutritional outcome or a predictor variable? J Nutr 121, 408-415.

4. Alaimo K, Olson CM, Frongillo EA Jr \& Briefel RR (2001) Food insufficiency, family income, and health in US preschool and school-aged children. Am J Public Health 91, 781-786.

5. Alaimo K, Olson CM \& Frongillo EA Jr (2001) Food insufficiency and American school-aged children's cognitive, academic, and psychosocial development. Pediatrics 108, 44-53.

6. Murphy JM, Wehler CA, Pagano ME, Little M, Kleinman RE \& Jellinek MS (1998) Relationship between hunger and psychosocial functioning in low-income American children. J Am Acad Child Adolesc Psychiatry 37, 163-170.

7. Kleinman RE, Murphy JM, Little M, Pagano M, Wehler CA, Regal K \& Jellenik MS (1998) Hunger in children in the United States: potential behavioral and emotional correlates. Pediatrics 101, E3.

8. Cook JT (2002) Clinical implications of household food security: definitions, monitoring, and policy. Nutr Clin Care 5, 152-167.

9. Skolnick AA (1995) 'More!' Cry children as Congress shakes its head. JAMA 274, 783.

10. Townsend MS, Peerson J, Love B, Achterberg C \& Murphy SP (2001) Food insecurity is positively related to overweight in women. J Nutr 131, 1738-1745.

11. Casey PH, Simpson PM, Gossett JM et al. (2006) The association of child and household food insecurity with childhood overweight status. Pediatrics 118, e1406-e1413.

12. Looker AC, Dallman PR, Carroll MD, Gunter EW \& Johnson CL (1997) Prevalence of iron deficiency in the United States. JAMA 277, 973-976.

13. US Department of Health and Human Services (1996) Screening for Iron Deficiency Anemia including Iron Prophylaxis. Guide to Clinical Preventive Services, 2nd ed. Washington, DC: DHHS, Office of Disease Prevention and Health Promotion.

14. Grantham-McGregor S \& Ani C (2001) A review of studies on the effect of iron deficiency on cognitive development in children. J Nutr 131, 2 Suppl., 649S-666S.

15. Lozoff B, Brittenham GM, Wolf AW, McClish DK, Kuhnert PM, Jimenez E, Jimenez R, Mora LA, Gomez I \& Krauskoph D (1987) Iron deficiency anemia and iron therapy effects on infant developmental test performance. Pediatrics $\mathbf{7 9}$, 981-995.

16. Lozoff B, Jimenez E, Hagen J, Mollen E \& Wolf AW (2000) Poorer behavioral and developmental outcome more than 
10 years after treatment for iron deficiency in infancy. Pediatrics 105, E51.

17. Halterman JS, Kaczorowski JM, Aligne CA, Auinger P \& Szilagyi PG (2001) Iron deficiency and cognitive achievement among school-aged children and adolescents in the United States. Pediatrics 107, 1381-1386.

18. Rose D, Gundersen C \& Oliveira V (1998) Socio-economic Determinants of Food Insecurity in the United States. Evidence From the SIPP and CSFII Datasets. Washington, DC: US Department of Agriculture, Economic Research Service.

19. Skalicky A, Meyers AF, Adams WG, Yang Z, Cook JT \& Frank DA (2006) Child food insecurity and iron-deficiency anemia in low-income infants and toddlers in the United States. Matern Child Health J 10, 177-185.

20. Cook JT, Frank DA, Berkowitz C et al. (2002) Welfare reform and the health of young children: a sentinel survey in 6 US cities. Arch Pediatr Adolesc Med 156, 678-684.

21. Bickel G, Nord M, Price C, Hamilton W \& Cook JT (2000) Measuring Food Security in the United States. Guide to Measuring Household Food Security. Alexandria, VA: US Department of Agriculture, Food and Nutrition Service, Office of Analysis and Evaluation.

22. US Department of Agriculture (2008) Food Security in the United States: Hunger and Food Security. http://www. ers.usda.gov/Briefing/FoodSecurity/surveytools.htm (assessed October 2008).

23. Domellof M, Dewey KG, Lonnerdal B, Cohen RJ \& Hernell O (2002) The diagnostic criteria for iron deficiency in infants should be reevaluated. J Nutr 132, 3680-3686.

24. Hammond PB (1977) Exposure of humans to lead. Annu Rev Pharmacol Toxicol 17, 197-214.

25. Centers for Disease Control and Prevention (2005) Iron deficiency - United States, 1999-2000. MMWR Morb Mortal Wkly Rep 51, 897-899.

26. Kahn JL, Binns HJ, Chen T, Tanz RR \& Listernick R (2002) Persistence and emergence of anemia in children during participation in the Special Supplemental Nutrition Program for Women, Infants, and Children. Arch Pediatr Adolesc Med 156, 1028-1032.

27. Brotanek JM, Halterman JS, Auinger P, Flores G \& Weitzman M (2005) Iron deficiency, prolonged bottle-feeding, and racial/ethnic disparities in young children. Arch Pediatr Adolesc Med 159, 1038-1042.
28. Cusick SE, Mei Z \& Cogswell ME (2007) Continuing anemia prevention strategies are needed throughout early childhood in low-income preschool children. I Pediatr 150, 422-428.

29. Domellof M, Lonnerdal B, Dewey KG, Cohen RJ, Rivera LL \& Hernell O (2002) Sex differences in iron status during infancy. Pediatrics 110, 545-552.

30. Benton D (1992) Vitamin-mineral supplements and intelligence. Proc Nutr Soc 51, 295-302.

31. Oppenheimer SJ (2001) Iron and its relation to immunity and infectious disease. J Nutr 131, 2 Suppl., 616S-633S.

32. Mbofung CM, Atinmo T \& Omololu A (1984) Mineral content of colostrum and mature milk of lactating Nigerian women as influenced by stage of lactation. Nutr Rep Int 30, 1137-1146.

33. Dallman PR (1986) Iron deficiency in the weanling: a nutritional problem on the way to resolution. Acta Paediatr Scand Suppl 323, 59-67.

34. Meinzen-Derr JK, Guerrero ML, Altaye M, Ortega-Gallegos H, Ruiz-Palacios GM \& Morrow AL (2006) Risk of infant anemia is associated with exclusive breast-feeding and maternal anemia in a Mexican cohort. J Nutr 136, 452-458.

35. Colomer J, Colomer C, Gutierrez D, Jubert A, Nolasco A, Donat J, Fernandez-Delgado R, Donat F \& Alvarez-Dardet C (1990) Anaemia during pregnancy as a risk factor for infant iron deficiency: report from the Valencia Infant Anaemia Cohort (VIAC) study. Paediatr Perinat Epidemiol 4, 196-204.

36. De Pee S, Bloem MW, Sari M, Kiess L, Yip R \& Kosen S (2002) The high prevalence of low hemoglobin concentration among Indonesian infants aged 3-5 months is related to maternal anemia. J Nutr 132, 2215-2221.

37. Miller V, Swaney S \& Deinard A (1985) Impact of the WIC program on the iron status of infants. Pediatrics 75, 100-105.

38. Owen AL \& Owen GM (1997) Twenty years of WIC: a review of some effects of the program. J Am Diet Assoc 97, 777-782.

39. Batten S, Hirschman J \& Thomas D (1990) Impact of the Special Supplemental Food Program on infants. J Pediatr 117, S101-S109.

40. US Department of Health and Human Services (2000) Healthy People 2010, 2nd ed. vols 1 and 2: Understanding and Improving Health and Objectives for Improving Health. Washington, DC: DHHS. 